\title{
Sulfur-based mixotrophic denitrification corresponding to different electron donors and microbial profiling in anoxic fluidized-bed membrane bioreactors
}

\author{
Lili Zhang a, b, c, Chao Zhang ${ }^{\text {a, }}$ Chengzhi Hu ${ }^{\text {a, }}{ }^{*}$, Huijuan Liu ${ }^{\text {a }}$, Yaohui Bai a, Jiuhui Qu ${ }^{\text {a }}$ \\ ${ }^{a}$ Key Laboratory of Drinking Water Science and Technology, Research Center for Eco-Environmental Sciences, Chinese Academy of Sciences, Beijing 100085, \\ China \\ ${ }^{\mathrm{b}}$ Research Center of the Ministry of Education for High Gravity Engineering and Technology, Beijing University of Chemical Technology, Beijing 100029, \\ China \\ c State Key Laboratory of Organic-Inorganic Composites, Beijing University of Chemical Technology, Beijing 100029, China
}

\section{A R T I C L E I N F O}

\section{Article history:}

Received 9 April 2015

Received in revised form

26 July 2015

Accepted 30 August 2015

Available online 4 September 2015

\section{Keywords}

Sulfur-based mixotrophic denitrification

AnFB-MBR

Pyrosequencing

Microbial community

\begin{abstract}
A B S T R A C T
Sulfur-based mixotrophic denitrifying anoxic fluidized bed membrane bioreactors (AnFB-MBR) were developed for the treatment of nitrate-contaminated groundwater with minimized sulfate production. The nitrate removal rates obtained in the methanol- and ethanol-fed mixotrophic denitrifying AnFB-MBRs reached 1.44-3.84 $\mathrm{g} \mathrm{NO}_{3}{ }^{-}-\mathrm{N} / \mathrm{L}_{\text {reactor }} \mathrm{d}$ at a hydraulic retention time of $0.5 \mathrm{~h}$, which were significantly superior to those reported in packed bed reactors. Compared to methanol, ethanol was found to be a more effective external carbon source for sulfur-based mixotrophic denitrification due to lower sulfate and total organic carbon concentrations in the effluent. Using pyrosequencing, the phylotypes of primary microbial groups in the reactor, including sulfur-oxidizing autotrophic denitrifiers, methanol- or ethanol-supported heterotrophic denitrifiers, were investigated in response to changes in electron donors. Principal component and heatmap analyses indicated that selection of electron donating substrates largely determined the microbial community structure. The abundance of Thiobacillus decreased from $45.1 \%$ in the sulfur-oxidizing autotrophic denitrifying reactor to $12.0 \%$ and $14.2 \%$ in sulfur-based methanol- and ethanol-fed mixotrophic denitrifying bioreactors, respectively. Heterotrophic Methyloversatilis and Thauera bacteria became more dominant in the mixotrophic denitrifying bioreactors, which were possibly responsible for the observed methanol- and ethanol-associated denitrification.
\end{abstract}

(C) 2015 Elsevier Ltd. All rights reserved.

\section{Introduction}

Nitrate $\left(\mathrm{NO}_{3}{ }^{-}\right)$is a prevalent contaminant in groundwater. Pollution of drinking water with nitrate presents a serious health hazard because at concentrations higher than $10 \mathrm{mg} \mathrm{N} / \mathrm{L}$, nitrite formed may lead to methemoglobinemia or blue baby syndrome in infants and gastrointestinal cancer in adults (Fonseca et al., 2000; Ward et al., 2005). Groundwater polluted by nitrates typically contains almost no organic matter, thus sulfur-based autotrophic denitrification as illustrated in Eq. (1) has been reported to be an alternative for the removal of nitrate in contaminated drinking water (Sierra-Alvarez et al., 2007; Sahinkaya et al., 2011; Sahinkaya and Kilic, 2014).

\footnotetext{
* Corresponding author.

E-mail address: czhu@rcees.ac.cn (C. Hu).
}

$$
\begin{aligned}
& 55 \mathrm{~S}^{0}+20 \mathrm{CO}_{2}+50 \mathrm{NO}_{3}{ }^{-}+38 \mathrm{H}_{2} \mathrm{O}+4 \mathrm{NH}_{4}{ }^{+} \rightarrow 4 \mathrm{C}_{5} \mathrm{H}_{7} \mathrm{O}_{2} \mathrm{~N} \\
& +55 \mathrm{SO}_{4}{ }^{2-}+25 \mathrm{~N}_{2}+64 \mathrm{H}^{+}
\end{aligned}
$$

To date, packed bed reactors have been predominantly employed for sulfur-based autotrophic denitrification (SierraAlvarez et al., 2007; Sahinkaya et al., 2011; Sahinkaya and Kilic, 2014; Sun and Nemati, 2012; Zhang and Zeng, 2006). However, such systems often suffer from mass transfer limitation and are hampered by low nitrate loading rates in full-scale applications. Moreover, post-treatment is generally required to remove sloughed biomass from the product water, resulting in additional treatment cost.

Fluidized bed bioreactor is considered to be a high-rate reactor configuration because it has good mass transfer characteristics (Kim et al., 2011). The current challenge for application of anaerobic fluidized bed bioreactors lies in effective solid liquid separation in 
order to control biomass retention as well as to improve effluent quality. In fact, this problem can be easily overcome by adopting membrane bioreactor (MBR). Recently, AnFB-MBRs have been considered as a suitable technology for handling dilute wastewater (Gao et al., 2014; McCurry et al., 2014; Sahinkaya et al., 2015). For example, lab-scale extractive and diffusive MBRs have been applied for the heterotrophic/autotrophic denitrification of drinking water (McAdam and Judd, 2007; Zhao et al., 2013), whereas a sulfuroxidizing autotrophic denitrifying AnFB-MBR had also been developed for the treatment of nitrate-contaminated drinking water (Zhang et al., 2015).

In all sulfur-oxidizing autotrophic denitrification processes, sulfate formation leads to high sulfate content in treated effluent (Sahinkaya and Kilic, 2014). The allowable limit of sulfate for drinking water set by the US EPA is $250 \mathrm{mg} / \mathrm{L}$ (Oh et al., 2001). Theoretically, around $33 \mathrm{mg} / \mathrm{L} \mathrm{NO}_{3}{ }^{-}-\mathrm{N}$ could be denitrified without exceeding the above limit if water does not contain background sulfate (Sahinkaya et al., 2011). So, for higher nitrate concentrations, the control of excess sulfate production is a serious challenge. The mixotrophic process combining autotrophic and heterotrophic denitrification is an effective strategy to control sulfate formation since heterotrophic denitrifiers share fractions of autotrophic denitrification. Liu et al. (2009) utilized separate reactors for heterotrophic and sulfur-based autotrophic processes, which might increase process costs. Sahinkaya and Kilic (2014) reported that simultaneous sulfur-based autotrophic and heterotrophic denitrification could be achieved in a packed bed reactor to decrease sulfate production for drinking water treatment. Although methanol has been most commonly used in the previous studies (Sahinkaya et al., 2011; Sahinkaya and Kilic, 2014; Liu et al., 2009), mixotrophic processes have adopted alternative external carbon sources due to the increasing costs of methanol. Ethanol, though also expensive, can foster significantly higher denitrification rates (Lu and Chandran, 2010). However, to our knowledge sulfur-based mixotrophic denitrification established in AnFB-MBRs has not been reported so far, and the impact of specific carbon source on sulfate generation and denitrifying performance has received limited attention. For novel sulfur-based mixotrophic denitrifying processes, examining the microbial community structures is necessary to understand the complex interactions occurring in mixotrophic denitrification and find ways to improve the design and operation of scale-up systems. However, the co-existence of both heterotrophs and autotrophs in the microbial community makes the optimization and operation of such a process much more difficult. A mechanistic understanding of denitrifying microbial fractions in the sulfur-based mixotrophic denitrification is lacking.

Here, we studied sulfur-based mixotrophic denitrification with different electron donating substrates in a novel AnFB-MBR system to achieve complete nitrate removal and reduce sulfate generation. The objectives of this study were to: (1) compare the performance of methanol- and ethanol-fed sulfur-based mixotrophic denitrification and sulfate production, and demonstrate the feasibility of the sulfur-based mixotrophic denitrifying AnFB-MBR system; and
(2) provide insight into the microbial community composition to better predict how communities assemble in these ecosystems.

\section{Materials and methods}

\subsection{AnFB-MBR setup and operation}

The experimental setup was presented in Fig. S1 which is the same as reported by Zhang et al. (2015). In this study, two identical AnFB-MBR systems were operated under the same conditions except for external carbon. One reactor (R1) was operated with methanol supplement, and the other (R2) with ethanol addition. The enriched sulfur-oxidizing autotrophic denitrifying mixed culture was employed as the inoculum. Initially about $200 \mathrm{~g}$ of sulfur particles $(50-200 \mu \mathrm{m})$ were added to AnFB-MBR as an electron donor. A top-up $50 \mathrm{~g}$ of sulfur particles was supplemented after 60 days of operation to maintain a relatively stable sulfur content in the AnFB-MBR. From day 31 onwards, methanol and ethanol as external carbon sources were introduced into R1 and R2, respectively. Detailed operational conditions of R1 and R2 are summarized in Table 1. Methanol and ethanol were supplemented according to about $40-200 \%$ of theoretical requirements of heterotrophic denitrification.

An overhead mixer with a rotating speed of $450 \mathrm{rpm}$ was used to maintain fluidization of the sulfur particles. A liquid level indicator was connected to a peristaltic pump to maintain a constant water level at the top of the AnFB-MBR. Changes in the transmembrane pressure (TMP) were monitored with a vacuum pressure meter. The AnFB-MBRs were operated at $28 \pm 3^{\circ} \mathrm{C}$. The composition of the feed solution can be found elsewhere (Zhang et al., 2015), which was tap water amended with the $\mathrm{NO}_{3}{ }^{-}$concentration as $\mathrm{N}$, the $\mathrm{PO}_{4}{ }^{-}$concentration as $\mathrm{P}$, the total alkalinity of the feed and trace element solution.

\subsection{Continuous and batch experiments}

The conversion of substrates was monitored periodically by measuring the influent concentrations of nitrate, and the effluent concentrations of nitrate, nitrite, sulfate, and total organic carbon (TOC). When the AnFB-MBR was continuously operated until TMP increased by $0.3 \mathrm{bar}$, the membrane module was taken out of the bioreactor and replaced with a clean membrane. The fouled membrane was soaked in $0.5 \% \mathrm{NaOCl}$ solution overnight, followed by thorough flushing with deionized water.

The conversion of $\mathrm{NO}_{3}{ }^{-}-\mathrm{N}$ and $\mathrm{N}$-balance of the sulfur-based mixotrophic denitrifying process were elucidated with a ${ }^{15} \mathrm{~N}$ tracer technique. The bath assays were conducted in glass serum flasks $(500 \mathrm{~mL})$ supplemented with $200 \mathrm{~mL}$ of medium free of $\mathrm{NH}_{4}{ }^{+}-\mathrm{N} .{ }^{15} \mathrm{~N}-\mathrm{NO}_{3}{ }^{-}$expresses the nitrogen isotope ${ }^{15} \mathrm{~N}$ of the nitrate $\left(\mathrm{NO}_{3}{ }^{-}\right)$as a sole nitrogen substrate. The mineral medium $(\mathrm{pH}$ 7.5) contained variable concentrations of ${ }^{15} \mathrm{~N}$-labeling potassium nitrate $\left(\mathrm{K}^{15} \mathrm{NO}_{3}\right)$ with 99.7 atom\% ${ }^{15} \mathrm{~N}$. The experiments were inoculated with $0.2 \mathrm{~g} \mathrm{SS} / \mathrm{L}$ of the denitrifying culture and elemental

Table 1

Operational conditions of the R1 and R2.

\begin{tabular}{|c|c|c|c|c|c|c|}
\hline Operating periods & 1 & & & II & III & IV \\
\hline Days & $0-12$ & $13-20$ & $21-30$ & $31-80$ & $81-118$ & $119-180$ \\
\hline $\mathrm{NO}^{3-}-\mathrm{N}(\mathrm{mg} / \mathrm{L})$ & 30 & 50 & 80 & 30 & 50 & 80 \\
\hline $\begin{array}{l}\text { R1 } \\
\text { Methanol (mg/L) }\end{array}$ & 0 & 0 & 0 & $32.0-124.0(12.4-48.3)$ & $120.9-129.1(47.1-50.3)$ & $123.2-419.6(48.0-163.5)$ \\
\hline $\begin{array}{l}\text { R2 } \\
\text { Ethanol }(\mathrm{mg} / \mathrm{L})^{\mathrm{a}}\end{array}$ & 0 & 0 & 0 & $23.7-92.1(12.7-48.0)$ & $90.1-100.5(48.2-52.4)$ & $97.7-316.0(50.7-164.0)$ \\
\hline
\end{tabular}

${ }^{a}$ Values in parenthesis shows the methanol or ethanol concentrations as TOC. 
sulfur particles from the AnFB-MBR. The headspace was flushed with high-purity helium to exclude oxygen and background nitrogen from the assays. All flasks were sealed with butyl rubber stoppers and aluminum crimp seals.

\subsection{Chemical analyses}

Nitrate, nitrite, and sulfate were determined by ion chromatography (IC) (Dionex ICS 2000, USA). The IC had an AS19 column $(4 \times 250 \mathrm{~mm})$ and $\mathrm{AG} 19$ precolumn $(4 \times 50 \mathrm{~mm})$, an eluent of $30 \mathrm{mM} \mathrm{KOH}$, and an eluent flow rate of $1 \mathrm{~mL} / \mathrm{min}$. The injection volume was $20 \mu \mathrm{L}$. Liquid samples were membrane filtered $(0.2 \mu \mathrm{m})$ prior to chromatographic analysis. The retention time of $\mathrm{NO}_{3}{ }^{-}$, $\mathrm{NO}_{2}{ }^{-}$, and $\mathrm{SO}_{4}{ }^{2-}$ were $10.2,6.3$, and $7.9 \mathrm{~min}$, respectively. The TOC concentrations in the influent and effluent were measured using a TOC/TN-VCSH analyzer (Shimadzu, Japan). Biomass was characterized by protein content in suspended solids. The protein content was determined using the modified Lowry method (Frølund et al., 1995). Both $\mathrm{N}_{2}$ and $\mathrm{N}_{2} \mathrm{O}$ were determined by gas chromatography (GC) using a $6890 \mathrm{~N}$ system (Agilent Technologies, USA) and a SP3410 gas chromatograph (Beijing Beifen-Ruili Analytical Instrument Co. Ltd., China), respectively, as described by Zhang et al. (2015). The $\mathrm{N}_{2}$ and $\mathrm{N}_{2} \mathrm{O}$ samples were collected from the headspace of the sealed serum flasks using a gas tight syringe and directly injected into the gas chromatography.

\section{4. $N$ isotope analysis}

The ${ }^{15} \mathrm{~N}$ fractions of ${ }^{15} \mathrm{~N}$-labeled $\mathrm{N}_{2}$ and $\mathrm{N}_{2} \mathrm{O}$ were determined by a Delta V Advantage Isotope Ratio Mass Spectrometer (IRMS, Thermo Fisher Scientific Inc., USA). The potential contribution to $\mathrm{N}_{2}$ and $\mathrm{N}_{2} \mathrm{O}$ formation of $\mathrm{NO}_{3}{ }^{-}$denitrification was calculated from ${ }^{15} \mathrm{~N}$-labeled $\mathrm{N}_{2}$ and $\mathrm{N}_{2} \mathrm{O}$. Analysis of ${ }^{15} \mathrm{~N}$ fractions in the biomass solid was also similar to that by Zhang et al. (2015). The analytical reproducibility was $0.2 \%$ for $\delta^{15} \mathrm{~N}$.

\subsection{Pyrosequencing procedure and data analysis}

Sludge samples were collected for all stages when the reactor reached a steady state. Genomic DNA was extracted using a Powersoil ${ }^{\circledR}$ DNA Isolation kit (MoBio Laboratories Inc., USA) according to the manufacturer's procedures. DNA of all samples was extracted in duplicate. The DNA extract samples were then frozen at $-80^{\circ} \mathrm{C}$ for pyrosequencing analysis. The DNA samples for 454 pyrosequencing were sent to Shanghai Majorbio Technology (Shanghai, China) for amplicon pyrosequencing with standard 454/GS-FLX protocols (Sun et al., 2011). The bacteria domain was targeted by selecting the $\mathrm{V} 1-\mathrm{V} 3$ region of the $16 \mathrm{~S}$ rRNA gene with primers $27 \mathrm{~F}\left(5^{\prime}\right.$-GAGTTTGATCNTGGCTCAG-3') and 533R (5'-TTACCGCGGCTGCTGGCAC-3'). The 16S rRNA sequences reported in this study were submitted to the Sequence Read Archive under accession number SRP051554.

The pyrosequencing raw data were processed using Mothur v.1.35.0 to remove sequences with $200 \mathrm{bps}$, homopolymers of more than $8 \mathrm{bps}$, primer mismatches, or average quality scores lower than 25, and chimeric sequences (Schloss et al., 2011). The operational taxonomic units (OTUs) at the 97\% sequence identity level were picked using uclust (Edgar, 2010). Representative sequences from each OUT were identified using the Ribosomal Database Project (RDP) classification method, with assignment of taxonomic identities using the Greengenes 16S rRNA gene database. Sequences were classified using an RDP classifier at an $80 \%$ confidence threshold (Wang et al., 2007). After phylogenetic allocation of the sequences down to the phylum, class and genus level, relative abundance of a given phylogenetic group was set as the number of sequences affiliated with that group divided by the total number of sequences per sample. Rarefaction curves, community richness estimators of Chao and Ace, and community diversity estimators of Shannon and Simpson were generated for each sample with the EstimateS program (Version 9.1.0, http://viceroy.eeb.uconn.edu/ estimateS). Heatmap analysis was performed using the gplots package of $\mathrm{R}$ (http://www.r-project.org/). Principal component analysis (PCA) was conducted by the vegan package of R. Venn diagrams of shared and unique OTUs were drawn to highlight the similarities and differences between the different analyzed samples.

\section{Results and discussion}

\subsection{Performance of mixotrophic AnFB-MBRs}

The two AnFB-MBRs (R1 and R2) were operated in parallel under autotrophic (period I) and mixotrophic (periods II-IV) conditions for 180 days (Table 1 ). Fig. 1 shows the concentration profiles of nitrate, nitrite, sulfate, TOC, theoretical sulfate production etc. In period I, R1 and R2 showed similar performance in denitrifying nitrate under the same operating conditions. Nitrate was removed to non-detectable levels, even though the influent $\mathrm{NO}_{3}{ }^{-}-\mathrm{N}$ concentration was increased from 30 to $80 \mathrm{mg} / \mathrm{L}$ at hydraulic retention times (HRT) of 0.5-1.5 h, respectively. From period II onwards, R1 and R2 were operated under mixotrophic conditions with addition of methanol and ethanol, respectively. Complete removal of nitrate was observed at an HRT of $0.5 \mathrm{~h}$, and nitrite was not detected in the effluent during periods II-IV, indicating consistently high denitrifying efficiencies in the two mixotrophic AnFB-MBRs.

For sulfur-based autotrophic denitrification, sulfate is produced during nitrate removal. Sulfate production was increased from 274.7 to $698.4 \mathrm{mg} / \mathrm{L}$ with the increase in influent $\mathrm{NO}_{3}{ }^{-}-\mathrm{N}$ concentrations from 30 to $80 \mathrm{mg} / \mathrm{L}$ in period I (Fig. 1), which was in good agreement with the theoretical predictions. From day 50 onwards, sulfate generation tended to decrease markedly with addition of the external carbon sources, implying that heterotrophic denitrification started to function in the mixotrophic bioreactors. In R1, with the addition of methanol of $12.4-50.3 \mathrm{mg} / \mathrm{L}$ TOC, sulfate concentrations in the effluent were below $250 \mathrm{mg} / \mathrm{L}$ (maximum level set by US EPA) at influent $\mathrm{NO}_{3}{ }^{-}-\mathrm{N}$ concentrations below $50 \mathrm{mg} / \mathrm{L}$. Effluent TOC was constantly below $5.0 \mathrm{mg} / \mathrm{L}$, indicating that the added methanol was utilized as a carbon source by heterotrophic or facultative chemolithoautotrophic denitrifiers. With increasing influent $\mathrm{NO}_{3}{ }^{-}-\mathrm{N}$ concentrations to $80.0 \mathrm{mg} / \mathrm{L}$, sulfate generated by sulfur-oxidizing autotrophs was in the range of 232.0-301.0 $\mathrm{mg} / \mathrm{L}$. It appears that addition of methanol at the concentrations of $146.4-163.6 \mathrm{mg} / \mathrm{L}$ TOC might mitigate sulfate generation significantly (Fig. 1), while it also led to high effluent TOC concentration of $6.5-17.3 \mathrm{mg} / \mathrm{L}$. For ethanol-fed R2, in periods II and III, sulfate concentrations in the effluent were less than $244.2 \mathrm{mg} / \mathrm{L}$ with the addition of $12.7-52.4 \mathrm{mg} / \mathrm{L}$ ethanol as TOC (Fig. 1). In period IV, the difference between the influent and effluent sulfate concentrations showed that on average $161.5 \mathrm{mg} / \mathrm{L}$ sulfate was generated in the mixotrophic R2. To denitrify $80.0 \mathrm{mg} / \mathrm{L}$ $\mathrm{NO}_{3}{ }^{-}-\mathrm{N}$ by the sulfur-based autotrophic denitrification, $603.4 \mathrm{mg} /$ L sulfate should be theoretically produced. These in turn suggest that heterotrophic denitrification induced by addition of ethanol was helpful for mitigating sulfate generation. In addition, residual TOC concentration in the effluent of $\mathrm{R} 2$ was constantly below $5.0 \mathrm{mg} / \mathrm{L}$ throughout the whole operation. Compared with methanol-fed R1, the lower sulfate generation and residual TOC concentration were observed in the ethanol-fed $\mathrm{R} 2$. This can be explained by the fact that denitrifying bacteria are more accessible to ethanol than methanol (Baytshtok et al., 2009). Some researchers also reported that ethanol fostered higher specific denitrification 


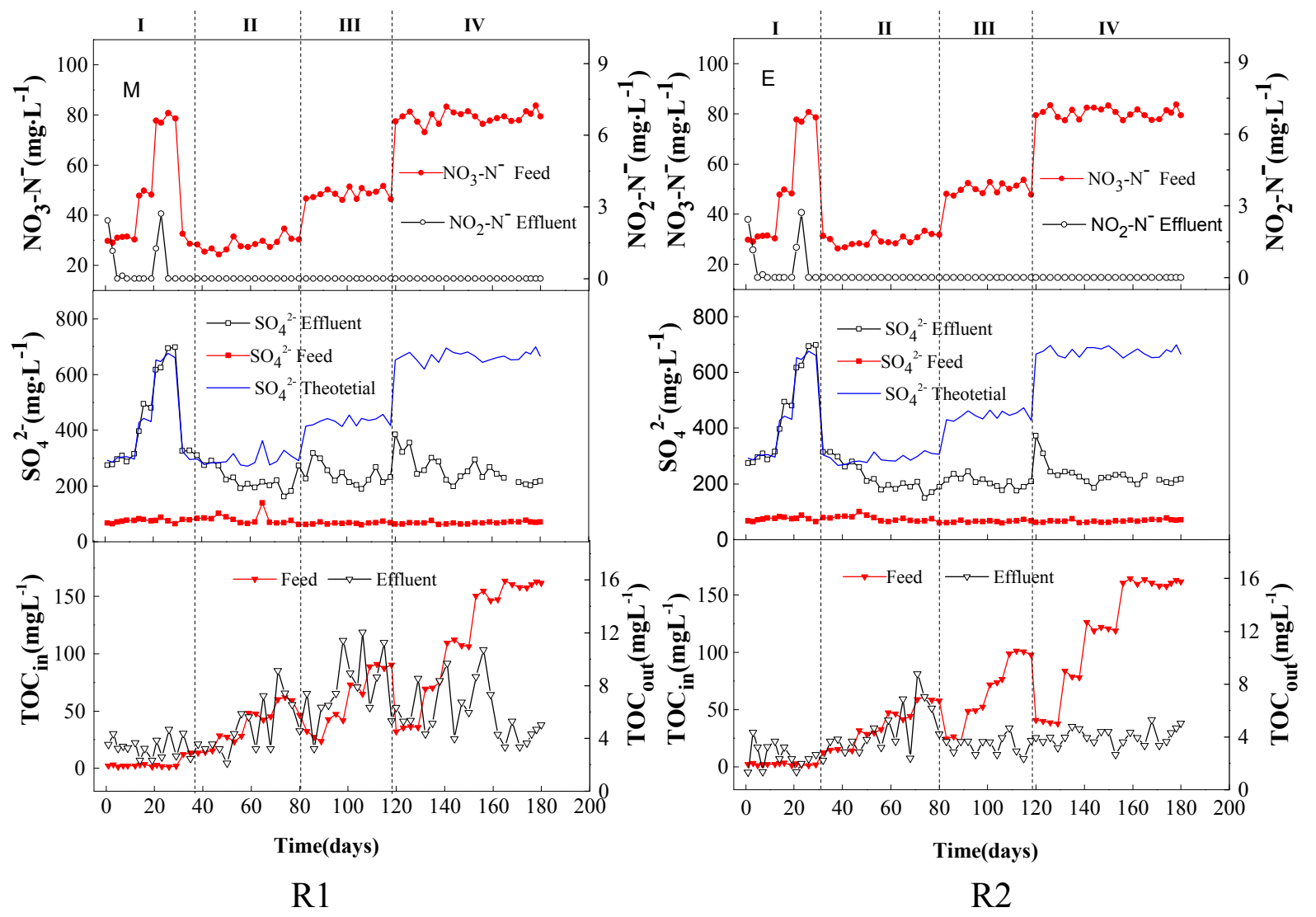

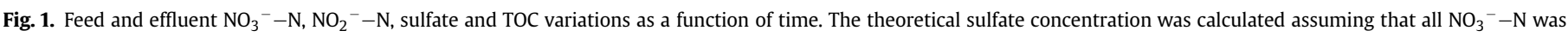

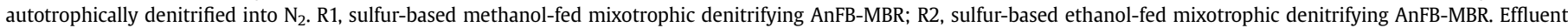
nitrate not shown because it was always non-detect. HRT in each period: $1.5 \sim 0.5 \mathrm{~h}$.

rates than methanol (Martin et al., 2009; Mokhayeri et al., 2008; Lu and Chandran, 2010; Salminen et al., 2014). The carbon source in a given system produces a strong impact on denitrifying performance as organic carbon and energy metabolism with diverse pathways form the foundation for heterotrophic growth.

Most sulfur-based denitrification has been realized in sulfurpacked bed reactors. In this study, we reported a novel sulfurbased mixotrophic denitrifying AnFB-MBR for groundwater denitrification, in which sulfur and microbes were fluidized to enhance the mass transfer and membrane was utilized for solid/liquid separator. Compared to the packed bed systems, the advantages of AnFB-MBR were complete biomass retention and good mass transfer due to the combining use of anoxic fluidized bed and membranes. During the long-term operation, the AnFB-MBRs were observed to achieve good denitrification performance. The nitrate removal rates reached $1.44-3.84 \mathrm{~g} \mathrm{NO}_{3}{ }^{-}-\mathrm{N} / \mathrm{L}_{\text {reactor }} \mathrm{d}$ when treating $30-80 \mathrm{mg} / \mathrm{L}$ of $\mathrm{NO}_{3}{ }^{-}-\mathrm{N}$ at an HRT of $0.5 \mathrm{~h}$. Such performances appeared to be much better than those reported in sulfur-based autotrophic and mixotrophic packed bed reactors (Table S1). In addition, it should be noted that the removal capacity of nitrate in the AnFB-MBR can be further improved if the HRT could be further shortened by increasing the membrane permeate flux. The high denitrification rate benefited from the absolute biomass retention and enhanced mass transfer in AnFB-MBRs. The speed at which a biological reaction can proceed and the manner in which the target pollutants contact the biomass are the major mechanisms determining the performance of bioreactors (Meng et al., 2013). For packed bed reactors, denitrification rate was mainly dependent on surface area of elemental sulfur (Sierra-Alvarez et al., 2007). Some pollutants may be discharged to the effluent without any contact with microbes due to the short-circuit phenomenon. In MBR, solids retention time and HRT can be controlled and adjusted separately, thus biomass retention is no longer an issue as compared to the activated sludge process. Biomass concentration has been known to play a vital role in many biological processes. The fluidized bed reactor could provide good mass transfer efficiency and well contact between biomass and bulk liquid (Gao et al., 2014; Kim et al., 2011). Therefore, the sulfur-based mixotrophic denitrifying AnFBMBR showed a significantly superior performance for nitrate removal compared against the conventional packed bed reactors. Also the AnFB-MBR can prevent secondary bacterial contamination of drinking water, and save the subsequent units to separate microorganism. Although AnFB-MBR capital costs were greater than conventional packed bed systems, the high denitrification rate and the lack of secondary clarifiers would reduce plant size significantly. The compact equipment and simple operation of the AnFB-MBR system suggests that it is suitable for decentralized direct potable use of nitrate-contaminated groundwater.

Fouling is a major problem limiting the long-term operation of MBRs and MBR-like systems (Meng et al., 2013). The change in TMP was used as an indicator of the extent of membrane fouling. The membrane performance was assessed by monitoring changes in permeate flux and TMP, as shown in Fig. 2. During the whole operation, the fluxes were maintained in the range of 4.1-12.2 L/ $\mathrm{m}^{2} \cdot \mathrm{h}$ which are comparable with those (about $5-10 \mathrm{~L} / \mathrm{m}^{2} \mathrm{~h}$ ) reported in anaerobic MBRs (Ho and Sung, 2010). No back-flushing was employed to simplify the operation of AnFB-MBR. Chemical cleaning of the membrane was carried out when TMP reached 


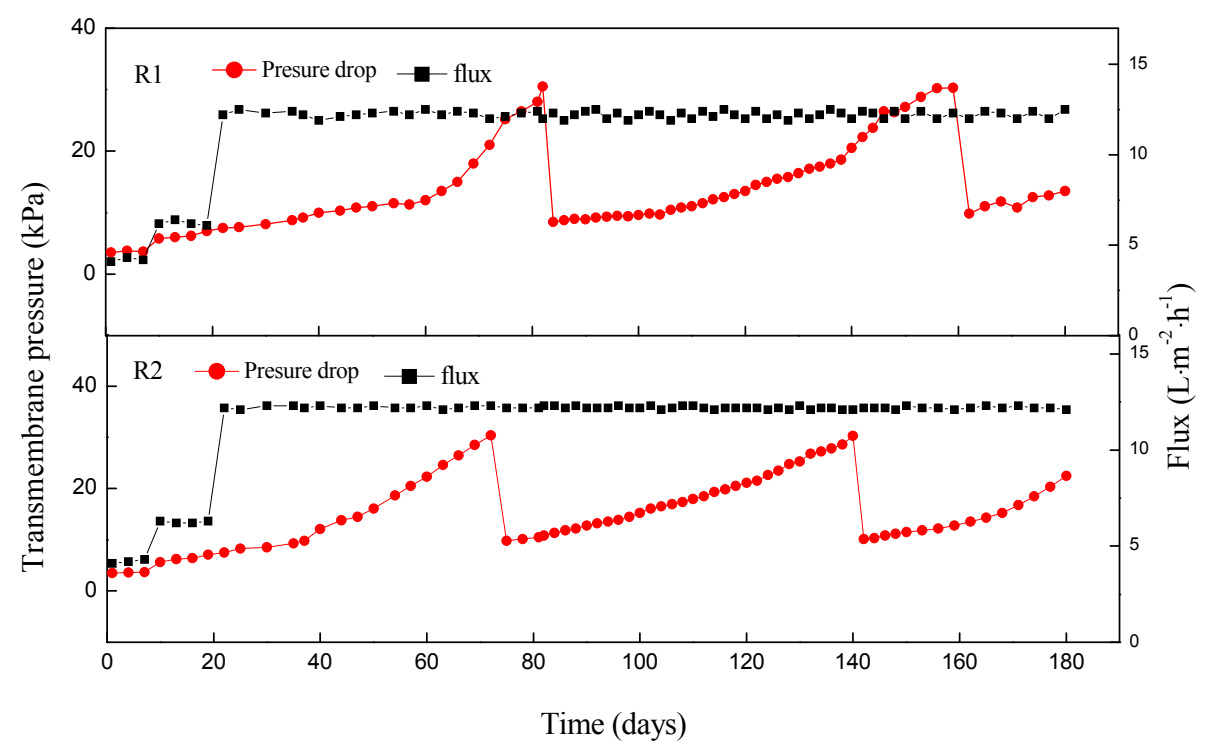

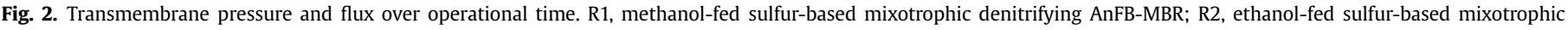
denitrifying AnFB-MBR.

$30 \mathrm{kPa}$ on day 82 for R1 and day 68 for R2. Then, the membrane module was reused throughout the whole operation. The success of the long-term operation for 180 days suggested that the AnFB-MBR provides a viable option for the treatment of nitrate-contaminated groundwater. Nevertheless, possible limitations must be addressed when scale-up is considered. For example, more research is required to optimize the loading rates and flux to obtain optimal reactor performance. The selection and optimization of membrane fouling control strategies will also be significant to achieve fullscale application.

\section{2. ${ }^{15} \mathrm{~N}$-labeling denitrification process}

The $\mathrm{NO}_{3}{ }^{-}-\mathrm{N}$ conversion and $\mathrm{N}$-balance in the sulfur-based mixotrophic denitrifying systems were elucidated with a ${ }^{15} \mathrm{~N}$ tracer technique. Fig. 3 shows concentration profiles of ${ }^{15} \mathrm{NO}_{3}{ }^{-}-\mathrm{N}$, ${ }^{15} \mathrm{NO}_{2}{ }^{-}-\mathrm{N},{ }^{15} \mathrm{~N}_{2} \mathrm{O}^{-}-\mathrm{N}$ and ${ }^{15} \mathrm{~N}_{2}-\mathrm{N}$ in the bioassays. Nitrate was completely consumed within $6 \mathrm{~h}$. The transient accumulation of nitrite produced from nitrate reduction was found to be 5.3, 4.3 and $1.4 \mathrm{mg} / \mathrm{L}^{15} \mathrm{NO}_{2}{ }^{-}-\mathrm{N}$ at 6,6 and $1.5 \mathrm{~h}$ for sulfur-oxidizing autotrophic denitrifiers, methanol- and ethanol-fed mixotrophic denitrifiers, respectively. $\mathrm{N}_{2} \mathrm{O}$ was another main intermediate in addition to nitrite during the sulfur-based denitrification of $\mathrm{NO}_{3}{ }^{-}-\mathrm{N}$. Peak ${ }^{15} \mathrm{~N}_{2} \mathrm{O}-\mathrm{N}$ concentrations $(0.072-0.102 \mathrm{mM}$ ) were observed in the first 2-6 h. Accumulation and conversion of $\mathrm{N}-$ oxide intermediates appeared to be associated with the selection of the carbon source. Nitrite and nitrous oxide concentrations for the ethanol-fed mixotrophic denitrification peaked before the methanol-fed process, and relatively lower nitrite and nitrous oxide accumulations were observed in the ethanol-fed process, indicating ethanol-fed mixotrophic denitrification had higher denitrification biokinetics than methanol. In fact, many commercially available carbon sources induce higher denitrification activity than methanol (Baytshtok et al., 2009; Bodík et al., 2009; Lu et al., 2014; Nyberg et al., 2004).

Nitrogen balances were determined to further elucidate the removal mechanisms of sulfur-based denitrification. Table 2 summarizes the ${ }^{15} \mathrm{NO}_{3}{ }^{-}-\mathrm{N}$ consumed, ${ }^{15} \mathrm{~N}_{2}-\mathrm{N}$ and ${ }^{15} \mathrm{~N}_{2} \mathrm{O}-\mathrm{N}$ released, and the ${ }^{15} \mathrm{~N}$-biomass formed. A nitrogen recovery of $96.7-104.7 \%$ was obtained for nitrate denitrification. Nitrogen converted to
${ }^{15} \mathrm{~N}_{2}-\mathrm{N}$ and ${ }^{15} \mathrm{~N}$-biomass accounted for $89.6-96.0 \%$ and $6.2-8.4 \%$ of the total nitrogen produced, respectively. These results indicated that nitrate was completely converted to $\mathrm{N}_{2}$ and biomass, with only $0.2-0.3 \%$ of removed nitrogen being ${ }^{15} \mathrm{~N}_{2} \mathrm{O}-\mathrm{N}$. This will help to reduce the potential of global climate change due to $\mathrm{N}_{2} \mathrm{O}$ emission.

\subsection{Comparative analysis of bacterial communities}

Pyrosequencing analysis generated a total of 67,484 high-quality sequences with a median length of $420 \mathrm{bp}$ for the 16S rRNA genes from all biomass samples of sulfur-oxidizing autotrophic denitrification (SAD), methanol-fed mixotrophic denitrification (MD-M), and ethanol-fed mixotrophic denitrification (MD-E). To determine the effects of carbon sources and nitrate loadings on the overall patterns of microbial community structure, PCA was performed for the sequences obtained from all detected samples. The PCA results revealed differences within the communities (Fig. 4). Principal components 1 and 2 explained $65.2 \%$ and $11.0 \%$ of total community variations, respectively. Three groups were distinguished among the SAD, MD-M and MD-E samples. In particular, the MD-M and MD-E samples were well separated from those of SAD along the principal component 1 ( $\mathrm{PC} 1$ ) vector, indicating that the microbial communities in mixotrophic denitrifying AnFB-MBRs were close to each other along the PC1 vector, while those samples in SAD were distant. These suggest that the addition of methanol or ethanol had a clear effect on the microbial community structure. For a given system, the carbon source has a remarkable potential impact on the denitrifying community structure than others, as organic carbon determines various metabolic pathways of heterotrophic bacteria (Baytshtok et al., 2009; Lu et al., 2014; Hallin et al., 2006; Wan et al., 2011; Lu et al., 2012).

To visualize the differences in the three bacterial community structures, cluster analysis was performed on detected samples (Fig. 5). The MD-M and MD-E samples formed a large cluster, while the SAD samples formed another. In consistent with the PCA results, heatmap analysis also showed clear distinctions in the community structure between sulfur-based autotrophic and mixotrophic denitrifying AnFB-MBRs, though they shared the same microbial consortia source. The overall community was dramatically affected when mixotrophic denitrification was enhanced with 

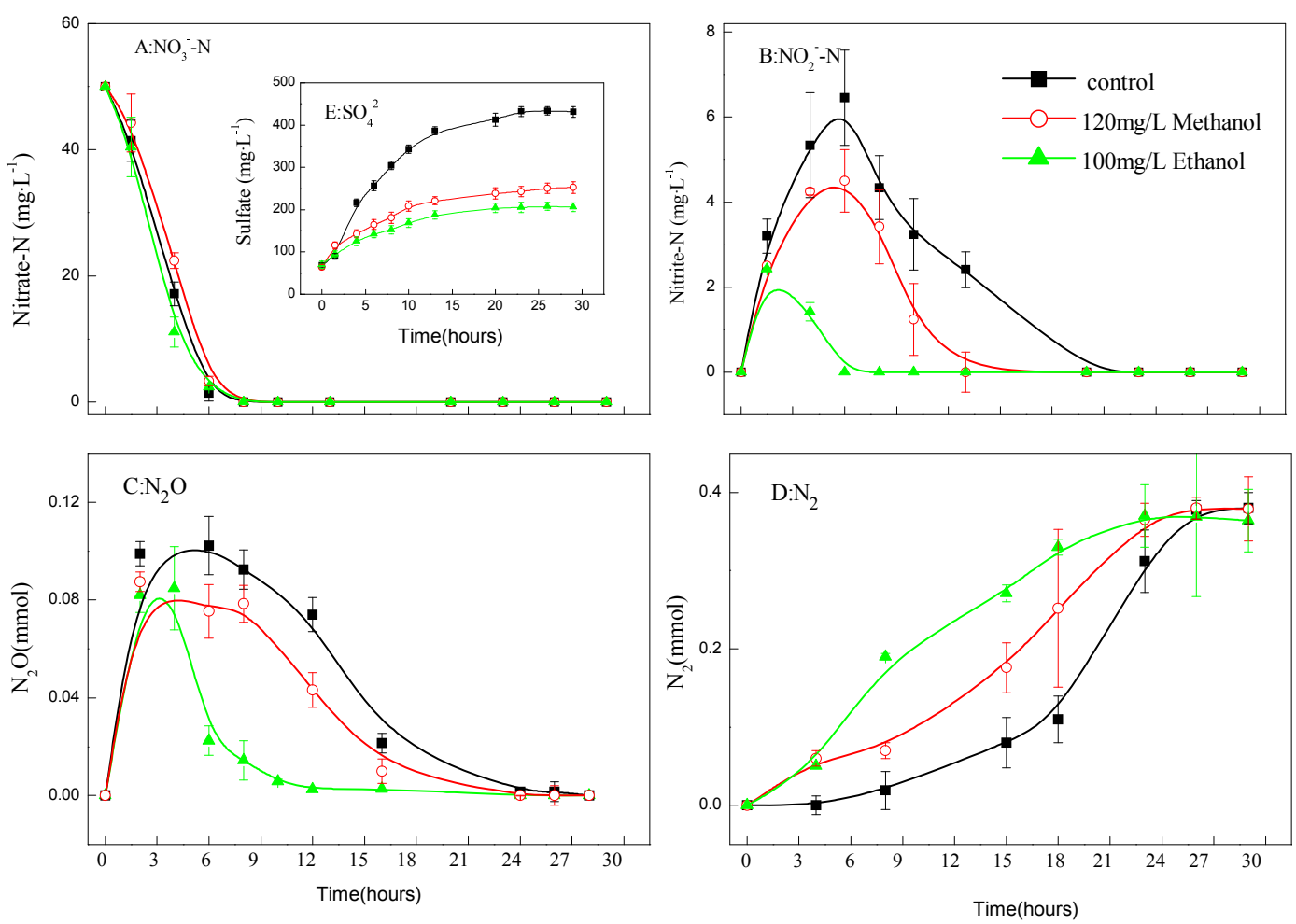

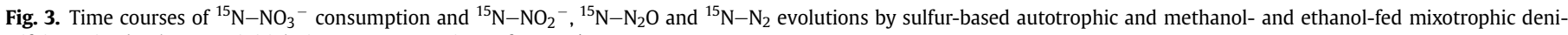
trifying mixed cultures at initial nitrate concentrations of $50 \mathrm{mg} / \mathrm{L} \mathrm{NO}_{3}{ }^{-}-\mathrm{N}$.

Table 2

Nitrogen balance and recovery of sulfur-oxidizing autotrophic and mixotrophic denitrification processes by ${ }^{15} \mathrm{~N}$-tracer technique.

\begin{tabular}{|c|c|c|c|c|c|}
\hline & Total ${ }^{15} \mathrm{~N}-\mathrm{NO}_{3}{ }^{-}(\mathrm{mg} / \mathrm{L} / \mathrm{mM})$ & ${ }^{15} \mathrm{~N}-\mathrm{N}_{2} \mathrm{O}(\mathrm{mM})$ & ${ }^{15} \mathrm{~N}-\mathrm{N}_{2}(\mathrm{mM})$ & ${ }^{15} \mathrm{~N}$-biomass $(\mathrm{mM})$ & ${ }^{15} \mathrm{~N}$ recovery $(\%)$ \\
\hline SAD & $51.2 / 0.731$ & 0.00152 & 0.6892 & 0.0456 & $100.7 \%$ \\
\hline MD-M & $49.5 / 0.707$ & 0.00205 & 0.6332 & 0.0489 & $96.7 \%$ \\
\hline MD-E & $50.5 / 0.721$ & 0.00218 & 0.6920 & 0.0605 & $104.7 \%$ \\
\hline
\end{tabular}

the addition of methanol or ethanol. The MD-M and MD-E communities were clustered together, but formed two sub-clusters, indicating that various carbon sources led to different microbial communities.

The overlap of the different communities and the taxonomic identities of the shared OTUs are shown in Fig. 6, that illustrates the bacterial OTUs unique to an AnFB-MBR community, or shared by two or three microbial communities. A total of 2321 OTUs was observed in all three sulfur-based autotrophic and mixotrophic denitrifying communities. A core community consisting of 154 OTUs, or $6.6 \%$ of total OTUs, was shared by all the three AnFB-MBRs. Thiobacillus, Sulfurimonas, Ignavibacterium, Thauera, Sulfurovum, Massilia, Longilinea, and Geobacter species were common to the sulfur-based autotrophic and mixotrophic systems. MD-M and MDE had more OTUs in common $(371,17.6 \%)$ than with SAD (MD-M/ SAD, 217, 14.0\%; MD-E/SAD, 230, 13.3\%). The OTUs unique to each community numbered 216 (SAD), 824 (MD-M), and 771 (MD-E), accounting for $78.0 \%$ of the total number of observed OTUs. The high proportions of unique OTUs in the three samples indicated that each community had its own specific microbial composition.

Both MD-M and MD-E had higher microbial diversity than SAD, and the microbial diversity was higher for MD-M over MD-E based on rarefaction curves, OTUs, Chao 1 and Shannon indices (Fig. S3 and Table S2). Previous study also reported that the higher overall diversity in the methanol enriched denitrifying community than that in the ethanol enriched denitrifying community in denitrifying SBRs (Baytshtok et al., 2009; Hallin et al., 2006).

\subsection{Bacterial taxonomic identification}

To identify the phylogenetic diversity of bacterial communities in SAD, MD-M and MD-E systems, the qualified reads were further assigned to known phyla, classes and genera (Fig. 7). Overall, the sulfur-based autotrophic and mixotrophic denitrifying bacterial communities contained sequences from around 15 phyla (Fig. 7a), with the majority of the sequences belonging to Proteobacteria, Chlorobi, Chloroflexi, and Bacteroidetes. The sum of the four dominant phyla accounted for 93.9\% (SAD), 96.1\% (MD-M) and 95.7\% (MD-E) of the total reads. Proteobacteria was by far the largest phyla in the three communities $(59.9,69.5$ and $70.3 \%$ for SAD, MD-M and MD-E, respectively). The enrichment of Proteobacteria, Chlorobi, Chloroflexi and Bacteroidetes has been detected in previous studies on heterotrophic and chemolithotrophic denitrification (MorganSagastume et al., 2008; Fernández et al., 2009; Zhang et al., 2015; Zhao et al., 2013; Shao et al., 2010). At the class level, the majority of the sequences belonged to Betaproteobacteria, Epsilonproteobacteria, Deltaproteobacteria, Anaerolineae and Ignavibacteria (Fig. 7b). Betaproteobacteria was found to be the largest class in all analyzed communities (48.9, 64.7 and 34.7\% for SAD, MD-M and MD-E, respectively). These imply that the members of 


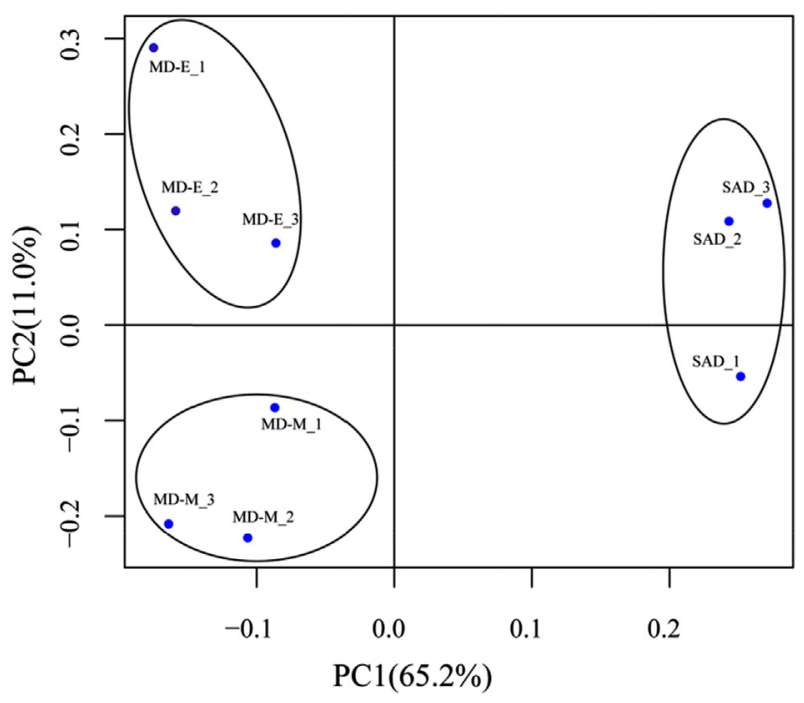

Fig. 4. Principal component analysis (PCA) of bacterial communities from different samples based on pyrosequencing of the 16S rRNA gene. The PC1 and PC2 axes represent $62.15 \%$ and $10.44 \%$ of the variance within the microbial community, respectively. SAD_1-3 correspond to sulfur-oxidizing autotrophic denitrification, with SAD_1 $=30 \mathrm{mg} / \mathrm{L} \mathrm{NO}_{3}{ }^{-}-\mathrm{N}, \mathrm{SAD} \_2=50 \mathrm{mg} / \mathrm{L} \mathrm{NO}_{3}{ }^{-}-\mathrm{N}$, and SAD_3 $=80 \mathrm{mg} / \mathrm{L}$ $\mathrm{NO}_{3}{ }^{-}-\mathrm{N}$. MD-M_1-3 correspond to methanol-fed mixotrophic denitrification, with MD-M_1 = $30 \mathrm{mg} / \mathrm{L} \mathrm{NO}_{3}{ }^{-}-\mathrm{N}, \mathrm{MD}-\mathrm{M} \_2=50 \mathrm{mg} / \mathrm{L} \mathrm{NO}_{3}{ }^{-}-\mathrm{N}$, and MD-M_3 $=80 \mathrm{mg} / \mathrm{L}$ $\mathrm{NO}_{3}{ }^{-}-\mathrm{N}$. MD-E_1 -3 correspond to ethanol-fed mixotrophic denitrification, with MDE_1 $=30 \mathrm{mg} / \mathrm{L} \mathrm{NO}_{3}{ }^{-}-\mathrm{N}, \mathrm{MD}-\mathrm{M} \_2=50 \mathrm{mg} / \mathrm{L} \mathrm{NO}_{3}{ }^{-}-\mathrm{N}$, and MD-M_3 $=80 \mathrm{mg} / \mathrm{L}$ $\mathrm{NO}_{3}{ }^{-}-\mathrm{N}$.

Betaproteobacteria were functionally relevant to denitrification in the systems studied. The dominance of Betaproteobacteria was consistent with identification in other reported denitrifying treatment systems (Morgan-Sagastume et al., 2008; Wrighton et al., 2014; Sayess et al., 2013).

The analyses based on the genus level can allow to further verify the function evolution of the community. Fig. 7c shows the relative proportions of the most abundant $(>1 \%)$ bacterial genera for the three denitrifying communities. For SAD, Thiobacillus (45.1\%), Ignavibacteriales (25.4\%), Sulfurimonas (7.0\%) and Longilinea (4.1\%) formed the dominant community structure. Thiobacillus and Sulfurimonas were the most commonly reported sulfur-oxidizing autotrophic denitrifiers (Fernández et al., 2009; Koenig et al., 2005; Shao et al., 2010). Ignavibacteriales and Longilinea were previously reported to be associated also with sulfur-based autotrophic denitrifying processes (Zhang et al., 2015). In MD-M, where methanol and sulfur were the mixotrophic electron donors, the dominant genera were Methyloversatilis (16.8\%), Thiobacillus (12.0\%), Thauera (5.1\%), Longilinea (2.2\%) and Hyphomicrobium (1.2\%). The dominant bacterial genera in MD-E included Thiobacillus (14.2\%), Sulfurimonas (13.1\%), Thauera (11.9\%), Geobacter (7.7\%), Ignavibacterium (5.8\%), Azospira (2.8\%), Anaerolinea (1.8\%), Longilinea (1.3\%), and Chryseobacterium (1.3\%). Thiobacillus was still a prominent bacterial phylotype even though it was obviously reduced in MD-M and MD-E systems, implying its autotrophic denitrification played a dominant role in nitrate removal in both sulfur-based autotrophic and mixotrophic denitrifying systems. Methyloversatilis was found to be the most abundant bacterial genera exclusively in MD-M. The significant enrichment of Methyloversatilis suggested an important functional role for these bacteria in methanol-fed heterotrophic denitrification. Indeed Methyloversatilis spp. have been known as a dominant bacterial genus in various methanol-fed denitrification systems (Baytshtok et al., 2009; Lu et al., 2014; Hallin et al., 2006), and can be further classified as obligate and facultative methylotrophs. Although less

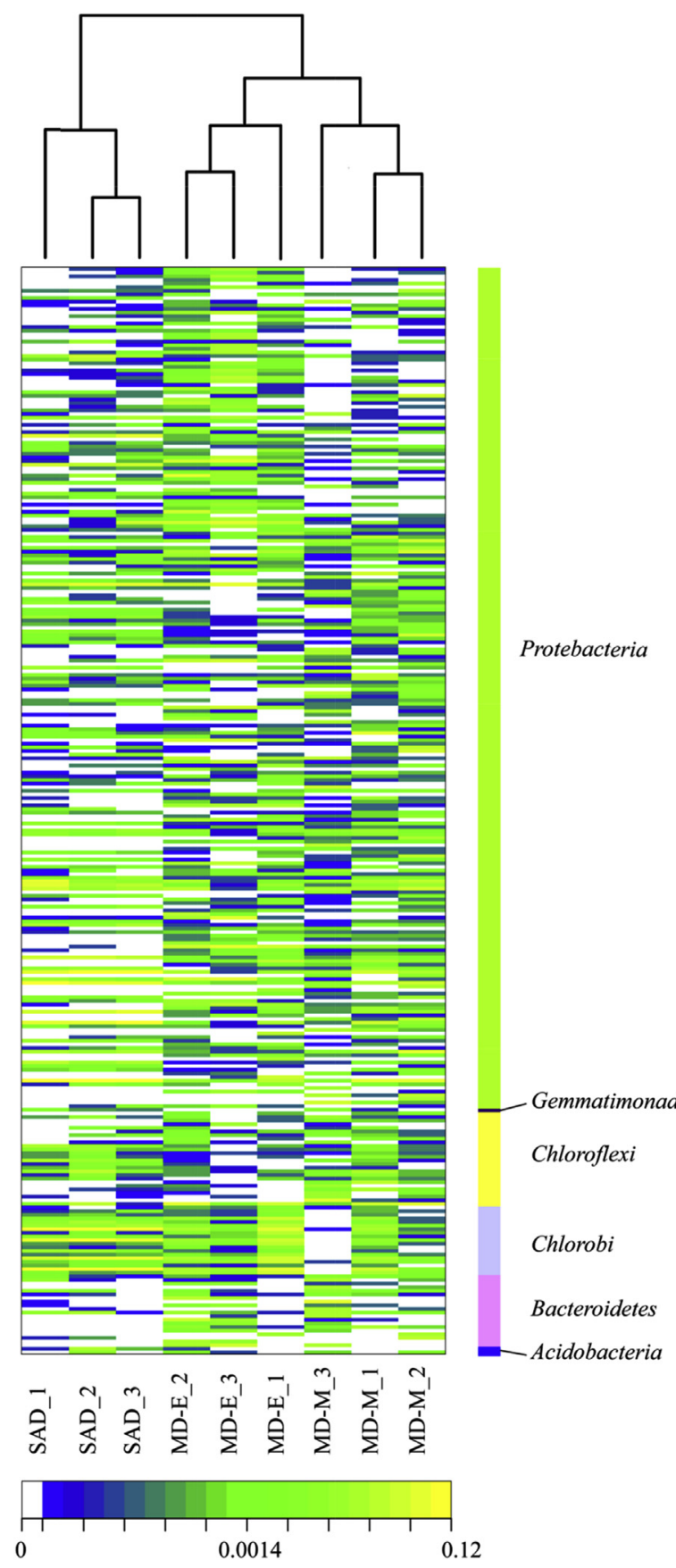

Fig. 5. Heatmap analysis of SAD, MD-M and MD-E bacterial communities. The $y$-axis is the clustering of the 300 most abundant OTUs (3\% distance) in reads. The OTUs were ordered by phylum. Sample communities were clustered based on the complete linkage method. The color intensity of scale indicates relative abundance of each OUT read. Relative abundance was defined as the number of sequences affiliated with that OUT divided by the total number of sequences per sample. (For interpretation of the references to color in this figure legend, the reader is referred to the web version of this article.)

abundant in MD-M, it is expected that Thauera (5.1\%) and Hyphomicrobium (1.2\%) might also be key methanol-utilizing denitrifying populations. Previously Thauera and Hyphomicrobium were also found to be methanol-assimilating bacteria under nitrate-reducing conditions (Baytshtok et al., 2009; Osaka et al., 2006). Thauera was the prominent bacterial genera in this MD-E except for the autotrophic microorganisms Thiobacillus, Sulfurimonas and Ignavibacterium shared by SAD and MD-E. Ethanol-fed denitrification 


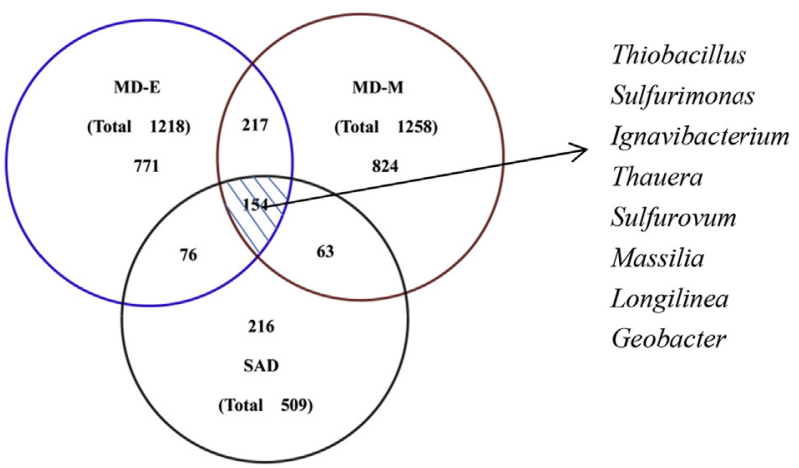

Fig. 6. Venn diagram showing the overlap of the different AnFB-MBR communities and the taxonomic identities of the shared OTUs. The number in parentheses represents the total number in that community. An OUT was defined by $5 \%$ sequence dissimilarity as a proxy for a genus. appeared to favor phylotypes closely related to Thauera, which was also the most abundant genus (48.48\%) in an earlier reported ethanol-supported denitrification system (Shen et al., 2013). Wagner and Loy (2002) also reported that the Thauera group represented abundant denitrifiers in an industrial wastewater treatment system. Anaerolinea was previously identified from an ethanol-supported system for nitrate removal (Shen et al., 2013). Compared with methanol, less is known about the molecular microbial ecology of ethanol-based denitrification. The genera Geobacter, Azospira and Chryseobacterium are also known to harbor denitrifiers in different denitrification systems (Gentile et al., 2007; Bellini et al., 2013; Heylen et al., 2006), though it is not clear about which of these communities actually assimilate ethanol during denitrification.

Microbial community functional structure plays an important role in bioreactor performance. Linking community structure to function is a fundamental issue in bioreactors (Liu et al., 2010). The

\section{a. Bacterial phyla}

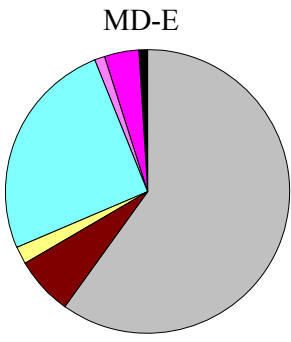

b. Bacterial classes

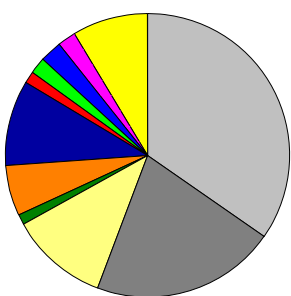

c. Bacterial genera

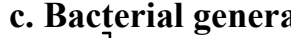



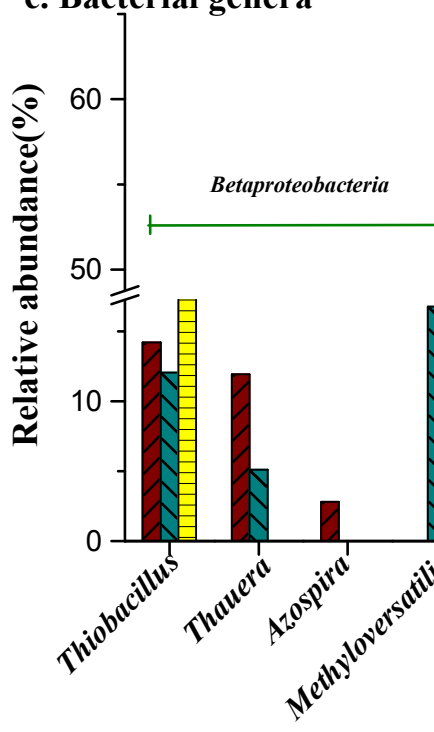

MD-M
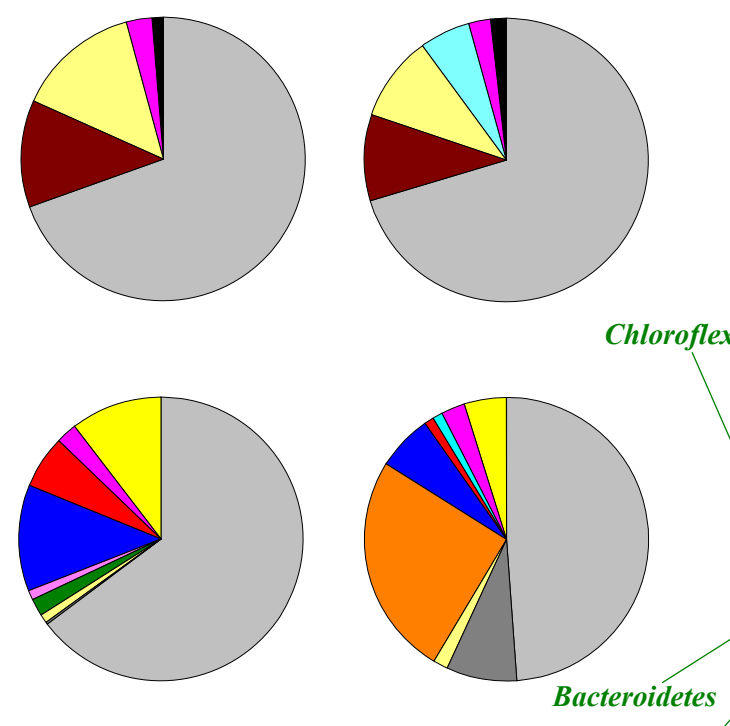

Acidobacteria
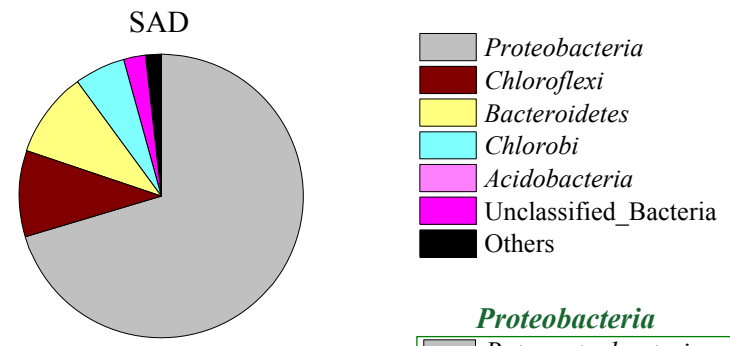

\section{Chloroflexi}
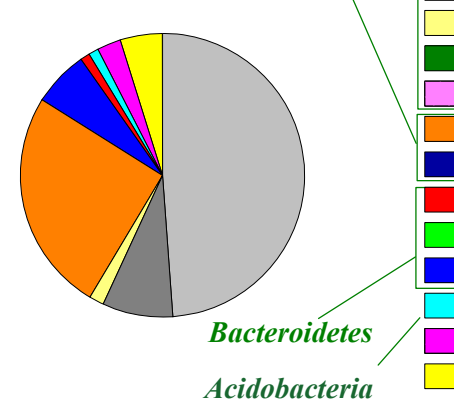

Proteobacteria Betaproteobacteria Epsilonproteobacteria

$\square$ Deltaproteobacteria

Alphaproteobacteria $\square$ Gammaproteobacteria

Ignavibacteria

Anaerolineae

Sphingobacteria

Flavobacteria

Bacteroidia

Acidobacteria Gp 7

Other

Unclassified bacterial 
above results indicate that changes in the community structure are consistent with the operational superiority of sulfur-based mixotrophic denitrifying AnFB-MBRs. As a corollary, our findings suggest that operation of reactors in mixotrophic modes results in a harmonious co-existence of autotrophic and heterotrophic microbes and an increased bacterial diversity of the active communities, which may have implications on the functional performance of these reactors. The 454 high-throughput pyrosequencing has revealed the significant impacts of electron donors on the microbial community structure and composition, and also provided novel insights into the selection of external carbon source for sulfurbased mixotrophic denitrifying AnFB-MBR from a microbiological perspective. Additional exploration of the communities in sulfurbased mixotrophic denitrification, with clearer variations in performance parameters, will allow us to establish more direct causeand-effect relationships between community structure and function.

\section{Conclusions}

In this work, sulfur-based mixotrophic denitrification supplied with different electron donators was investigated for complete nitrate reduction and mitigation of sulfate generation in AnFB-MBR systems. It was demonstrated that the sulfur-based mixotrophic denitrification in the AnFB-MBRs could effectively reduce $\mathrm{NO}_{3}{ }^{-}$to $\mathrm{N}_{2}$ with a decreased sulfate generation. Ethanol appeared to be a more effective external carbon source for control of sulfate production in the AnFB-MBRs. Electron donors were found to induce the shifts in the microbial community structures. The relative abundance of Thiobacillus decreased markedly in response to mixotrophic denitrification by the addition of methanol or ethanol, although it was still a dominant denitrifying bacteria phylotype shared in SAD, MD-M and MD-E. Likewise, heterotrophic bacteria Methyloversatilis and Thauera were possibly correlated with methanol- and ethanol-fed heterotrophic denitrification, and became more important in MD-M and MD-E, respectively. This study addressed the ecological interactions among heterotrophic and sulfur-oxidizing autotrophic denitrifiers for complete $\mathrm{NO}_{3}$ removal and control of $\mathrm{SO}_{4}{ }^{2-}$ generation in groundwater. It is important to apply ecological theory to integrate microbial ecology into ecosystem, which shift from purely descriptive study to predictive science. Based on the new understanding gained from dominant community members and their functional roles in sulfurbased mixotrophic denitrification processes, this study provided a practical guide for complete nitrate reduction without excess sulfate generation.

\section{Acknowledgments}

We acknowledge financial support from the National Natural Science Foundation of China (No. 51290282 and No. 21177116) and the Major Science and Technology Program for Water Pollution Control and Treatment (2012ZX07408001). We thank Dr. L Han and Ms. M Tian from the College of Life Science and Technology for substantial help in pyrosequencing analysis.

\section{Appendix A. Supplementary data}

Supplementary data related to this article can be found at http:// dx.doi.org/10.1016/j.watres.2015.08.055.

\section{References}

Baytshtok, V., Lu, H.J., Park, H., Kim, S., Yu, R., Chandran, K., 2009. Impact of varying electron donors on the molecular microbial ecology and biokinetics of methylotrophic denitrifying bacteria. Biotechnol. Bioeng. 102 (6), 1527-1536.

Bellini, M., Gutiérrez, L., Tarlera, S., Scavino, A.F., 2013. Isolation and functiona analysis of denitrifiers in an aquifer with high potential for denitrification. Syst. Appl. Microbiol. 36 (7), 505-516.

Bodík, I., Blštákováa, A., Sedláceka, S., Hutňana, M., 2009. Biodiesel waste as source of organic carbon for municipal WWTP denitrification. Bioresour. Technol. 100 (8), 2452-2456.

Edgar, R.C., 2010. Search and clustering orders of magnitude faster than blast. Bioinformatics 26 (19), 2460-2461.

Fernández, N., Sierra-Alvarez, R., Amils, R., Field, J.A., Sanz, J.L., 2009. Compared microbiology of granular sludge under autotrophic, mixotrophic and heterotrophic denitrification conditions. Water Sci. Technol. 59 (6), 1227-1236.

Fonseca, A.D., Crespo, J.G., Almeida, J.S., Reis, M.A., 2000. Drinking water denitrification using a novel ion-exchange membrane bioreactor. Environ. Sci. Technol. 34 (8), 1557-1562.

Frølund, B., Griebe, T., Nielsen, P.H., 1995. Enzymatic activity in the activated sludge floc matrix. Appl. Microbiol. Biotechnol. 43 (4), 755-761.

Gao, D.W., Hu, Q., Yao, C., Ren, N.Q., Wu, W.M., 2014. Integrated anaerobic fluidizedbed membrane bioreactor for domestic wastewater treatment. Chem. Eng. J. 240, 362-368.

Gentile, M.E., Jessup, C.M., Nyman, J.L., Criddle, C.S., 2007. Correlation of functional instability and community dynamics in denitrifying dispersed-growth reactors. Appl. Environ. Microbiol. 73 (3), 680-690.

Hallin, S., Throbäck, I.N., Dicksved, J., Pell, M., 2006. Metabolic profiles and genetic diversity of denitrifying communities in activated sludge after addition of methanol or ethanol. Appl. Environ. Microbiol. 72 (8), 5445-5452.

Heylen, K., Vanparys, B., Wittebolle, L., Verstraete, W., Boon, N., De Vos, P., 2006 Cultivation of denitrifying bacteria: optimization of isolation conditions and diversity study. Appl. Environ. Microbiol. 72 (4), 2637-2643.

Ho, J., Sung, S., 2010. Methanogenic activated in anaerobic membrane bioreactors (AnMBR) treating synthetic municipal wastewater. Bioresour. Technol. 101 (7), 2191-2196.

Kim, J., Kim, K., Ye, H., Lee, E., Shin, C., McCarty, P.L., Bae, J., 2011. Anaerobic fluidized bed membrane bioreactor for wastewater treatment. Environ. Sci. Technol. 45 2), 576-581.

Koenig, A., Zhang, T., Liu, L.H., Fang, H.H.H., 2005. Microbial community and biochemistry process in autotrophic denitrifying biofilm. Chemosphere 58 (8), $1041-1047$

Liu, H.J., Jiang, W., Wan, D.J., Qu, J.H., 2009. Study of a combined heterotrophic and sulfur autotrophic denitrification technology for removal of nitrate in water. J. Hazard. Mater: 169 (1-3), 23-28.

Liu, W.Z., Wang, A.J., Cheng, S.A., Logan, B.E., Yu, H., Deng, Y., Van Nostrand, J.D. Wu, L.Y., He, Z.L., Zhou, J.Z., 2010. Geochip-based functional gene analysis of anodophilic communities in microbial electrolysis cells under different operational modes. Environ. Sci. Technol. 44 (19), 7729-7735.

Lu, H.J., Chandran, K., 2010. Factors promoting emissions of nitrous oxide and nitric oxide from denitrifying sequencing batch reactors operated with methanol and ethanol as electron donors. Biotechnol. Bioeng. 106 (3), 390-398.

Lu, H.J., Chandran, K., Stensel, D., 2014. Microbial ecology of denitrification in biological wastewater treatment. Water Res. 64 (1), 237-254.

Lu, H., Kalyuzhnaya, M., Chandran, K., 2012. Comparative proteomic analysis reveals insights into anomic growth of Methyloversatilis universalis FAM5 on methanol and ethanol. Environ. Microbiol. 14 (11), 2935-2945.

Martin, D., Salminen, J.M., Niemi, R.M., Heiskanen, I.M., Valve, M.J., 2009. Acetate and ethanol as potential as potential enhancers of low temperature denitrification in soil contaminated by fur farms: a pilot-scale study. J. Hazard. Mater $163(2-3), 1230-1238$

McAdam, E.J., Judd, S.J., 2007. Denitrification from drinking water using a membrane bioreactor: chemical and biochemical feasibility. Water Res. 41 (18), 4242-4250.

McCurry, D.L., Bear, S.E., Bae, J., Sedlak, D.L., McCarty, P.L., Mitch, W.A., 2014. Superior removal of disinfection byproduct precursors and pharmaceuticals from wastewater in a staged anaerobic fluidized membrane bioreactor compared to activated sludge. Environ. Sci. Technol. Lett. 1 (11), 459-464.

Meng, F.G. Wang, Y. Huang, L.N., Li, J., Jiang, F., Li, S.Y., Chen, G.H., 2013. A novel nonwoven hybrid bioreactor (NWHBR) for enhancing simultaneous nitrification and denitrification. Biotechnol. Bioeng. 110 (7), 1903-1912.

Mokhayeri, Y., Riffat, R., Takacs, I.D.P., Bott, C., Hinojosa, J., Bailey, W., Murthy, S. 2008. Characterizing denitrification kinetics at cold temperature using various carbon sources in lab-scale sequencing batch reactors. Water Sci. Technol. 58 (1), 233-238.

Morgan-Sagastume, F., Nielsen, J.L., Nielsen, P.H., 2008. Substrate-dependent denitrification of abundant probe-defined denitrifying bacteria in activated sludge. FEMS Microbiol. Ecol. 66 (2), 447-461.

Nyberg, U., Andersson, B., Aspegren, H., 2004. Long-term experience with external carbon sources for nitrogen removal. Water Sci. Technol. 33 (12), 109-116.

Oh, S.E., Yoo, Y.B., Young, J.C., Kim, I.S., 2001. Effect of organics on sulfur-utilizing autotrophic denitrification under mixotrophic conditions. J. Biotechnol. 92 (1), $1-8$.

Osaka, T., Yoshie, S., Tsuneda, S., Hirata, A., Iwami, N., Inamori, Y., 2006. Identification of acetate- or methanol-assimilating bacteria under nitrate-reducing conditions by stable-isotope probing. Microb. Ecol. 52 (2), 253-266.

Sahinkaya, E., Dursun, N., Kilic, A., Demirel, S., Uyanik, S., Cinar, O., 2011. Simultaneous heterotrophic and sulfur-oxidizing autotrophic denitrification process for drinking water treatment: control of sulfate production. Water Res. 45 (20) 
6661-6667.

Sahinkaya, E., Kilic, A., 2014. Heterotrophic and elemental-sulfur-based autotrophic denitrification processes for simultaneous nitrate and $\mathrm{Cr}$ (VI) reduction. Water Res. 50 (1), 278-286.

Sahinkaya, E., Yurtsever, A., Aktaş, Ö., Ucar, D., Wang, Z.W., 2015. Sulfur-based autotrophic denitrification of drinking water using a membrane bioreactor. Chem. Eng. J. 268, 180-186.

Salminen, J.M., Petäjäjärvi, S.J., Tuominen, S.M., Nysten, T.H., 2014. Ethanol-based in situ bioremediation of acidified, nitrate-contaminated groundwater. Water Res. 63 (1), 306-315.

Sayess, R.R., Saikaly, P.E., El-Fadel, M., Li, D., Semerjian, L., 2013. Reactor performance in terms of COD and nitrogen removal and bacterial community structure of a three-stage rotating bioelectrochemical contactor. Water Res. 47 (2), $884-894$.

Schloss, P.D., Gevers, D., Westcott, S.L., 2011. Reducing the effects of PCR amplification and sequencing artifacts on 16S rRNA-based studies. PLoS One 6 (12) e27310.

Shao, M.F., Zhang, T., Fang, H.H.P., 2010. Sulfur-driven autotrophic denitrification: diversity, biochemistry, and engineering applications. Appl. Microbiol. Biotechnol. 88 (5), 1027-1042.

Shen, Z.Q., Zhou, Y.X., Wang, J.L., 2013. Comparison of denitrification performance and microbial diversity using starch/polylactic acid blends and ethanol as electron donor for nitrate removal. Bioresour. Technol. 131, 33-39.

Sierra-Alvarez, R., Beristain-Cardoso, R., Salazar, M., Gómez, J., Razo-Flores, E., Field, J.A., 2007. Chemolithotrophic denitrification with elemental sulfur for groundwater treatment. Water Res. 41 (6), 1253-1262.

Sun, Y.M., Nemati, M., 2012. Evaluation of sulfur-based autotrophic denitrification and denitritation for biological removal of nitrate and nitrite from contaminated waters. Bioresour. Technol. 114, 207-216.
Sun, Y., Wolcott, R.D., Dowd, S.E., 2011. Tag-encoded FLX amplicon pyrosequencing for the elucidation of microbial and functional gene diversity in any environment. Methods Mol. Biol. 733, 129-141.

Wan, C.Y., De Wever, H., Diels, L., Theoeye, C., Liang, J.B., Huang, L.N., 2011. Biodiversity and population dynamics of microorganisms in a full-scale membrane bioreactor for municipal wastewater treatment. Water Res. 45 (3), 1129-1138.

Wagner, M., Loy, A., 2002. Bacterial community composition and function in sewage treatment systems. Curr. Opin. Biotechnol. 13 (3), 218-227.

Wang, Q., Garrity, G.M., Tiedje, J.M., Cole, J.R., 2007. Naïve Bayesian classifier for rapid assignment of rRNA sequences into the new bacterial taxonomy. Appl. Environ. Microbiol. 73 (16), 5261-5267.

Ward, M.H., deKok, T.M., Levallois, P., Brender, J., Gulis, G., Nolan, B.T., VanDerslice, J., 2005. Workgroup report: drinking water nitrate and health-recent findings and research needs. Environ. Health Perspect. 113 (11), 1607-1614.

Wrighton, K.C., Virdis, B., Clauwaert, P., Read, S.T., Daly, R.A., Boon, N., Picena, Y., Andersen, G.L., Coates, J.D., Rabaey, K., 2014. Bacterial community structure corresponds to performance during cathodic nitrate reduction. ISME J. 4 (11), 1443-1455.

Zhang, L.L., Zhang, C., Liu, H.J., Qu, J.H., 2015. Denitrification of groundwater using a sulfur-oxidizing autotrophic denitrifying anaerobic fluidized-bed MBR: performance and bacterial community structure. Appl. Microbiol. Biotechnol. 99 (6), 2815-2827.

Zhang, T.C., Zeng, H., 2006. Development of a response surface for prediction of nitrate removal in sulfur-limestone autotrophic denitrification fixed-bed reactors. J. Environ. Eng. 132 (9), 1068-1072.

Zhao, H.P., Ilhan, Z.E., Ontiverors-Valencia, A., Tang, Y., Rittmann, B.E., 2013. Effects of multiple electron acceptors on microbial interactions in a hydrogen-based biofilm. Environ. Sci. Technol. 47 (13), 7396-7403. 